\title{
Diameter-height models for the Terai tree species
}

\begin{abstract}
A. Khadka ${ }^{1 *}$, T. Subedi ${ }^{1}$, M. Ghimire ${ }^{1}$, B. P. Dhakal ${ }^{1}$ and H. Parikka ${ }^{2}$
Tree diameter-height relationship can be used as a key input component in forest growth and yield models, and description of stand dynamics. Various models of stem diameter and height relation were developed. Those were formulated and implemented during Terai forest inventory data calculations in the Forest Resource Assessment (FRA) Nepal Project. The field inventory was conducted from December, 2010 to March, 2011. The Concentric Circular Sample Plot was designed where the diameters at breast height of all the tallied trees and the heights of the sampled trees were measured. The data were handled with $\mathrm{R}$-script in R Programme to generate non-linear mixed effects models in 'Imfor' package of forest biometrics functions of Mehtatalo. Different non-linear models were used to fit the diameter-height relation, which performed well in describing the relationships between the diameters and the heights of the Terai tree species depending on the sample size. The models were selected as the best fitted based on the statistical results such as standard error, Adjusted R², RMSE and residuals. The best models for Shorea robusta and Terminalia alata were generated using Wykoff's and Naslund's functions, respectively.
\end{abstract}

Key words: Growth, model, non-linear mixed effects, yield

$\mathrm{T}$ he Terai forests of Nepal are highly productive and economically important, yet underutilized resource in southern belt of Nepal. They represent around 20.41 percent of the Terai physiographic zone. The forests are characterized by sub-tropical forests consisting of Shorea robusta associated with the species like Terminalia tomentosa, $T$. bellirica, T. chebula, Anogeissus latifolia, Adina cordifolia, Albizia spp., Syzygium cumini, Acacia catechu and Dalbergia sissoo (DFRS, 2014). In order to fulfill the project purpose to improve the provision of adequate forestry data and its processing for national forest policy development and for national level forestry sector decision making, the Forest Resource Assessment (FRA) Nepal Project conducted the Terai field inventory from December, 2010 to March, 2011. Developing diameter-height models of non-linear mixed effects was one of the tasks during data calculations.

Accurate measurement of tree height is time consuming. Prediction of total tree height becomes very important in terms of regular monitoring of the forest resources as well as in conducting scientific forest researches. Diameter at breast height (dbh) is the most common variable measured easily and promptly, and can be used to predict tree-height. Predicting total tree-height based on observed diameter at breast height outside bark is routinely in practical management and silvicultural research work (Meyer, 1940). The estimation of tree volume, as well as the description of stands and their development over time, relies heavily on accurate height-diameter functions (Curtis, 1967).

Diameter-height relationships are used to estimate the heights of trees measured for their diameters at breast height. Such relationship describes the correlation between height and diameter of the trees in a stand on a given data, and can be represented by a linear or non-linear mathematical model. However, for diameter-height models, more care is needed, and a representative sample of accurately measured total-height is used as the response variable and $\mathrm{dbh}$ as the predictor variable (Mamoun, 2012).

Mixed models estimate both fixed and random parameters simultaneously for the same model. The introduction of random parameters into the model, specific for every sampling unit, enables us to model the variability detected for given phenomena among different locations, after defining a common fixed functional structure

\footnotetext{
Department of Forest Research and Survey (DFRS), Babarmahal, Kathmandu, Nepal,

* E-mail: anandakhadka@gmail.com

2 Finish Forest Research Institute, Joensuu, Finland
} 
(Lindstrom and Bates, 1990).

Mixed models give an unbiased and efficient estimation of the fixed parameters of the model. Furthermore, mixed models improve predictive ability if we are able to predict the value of the random parameters for an unsampled location. This is possible if complementary observations of the dependent variable are available. Determining the minimum size of this sub-sample to get the reliability required by forest managers is a basic decision to be confronted in inventory design since height measurement involves high costs (Houghton and Gregoire, 1993).

The objective of the study was to develop the diameter-height models and predict the heights for the major tree species of the Terai region, which were to be used in further calculations regarding volume and biomass.

\section{Materials and methods}

The study area covers the whole Terai region of Nepal. Two-phase cluster sampling method was applied. At the first-phase, a grid of $4 \mathrm{~km} \times 4 \mathrm{~km}$ was established, and at each grid point, a cluster of four plots was established. At the second phase, a sub-sample of the clusters was drawn for field measurements.

Concentric Circular Sample Plot (CCSP) was designed for field inventory. The CCSP consisted of four circular plots (Figure 1) with different radii per various tree diameter thresholds, respectively. All the established circles were centered at the same point. The outermost plot was used for tallying the bigger trees, whereas the inner plots were used for measuring the trees belonging to smaller-size classes.
The dbh of all the tallied trees and the heights of the sampled trees were measured during the field inventory. The dbh of the trees were measured at breast height (1.3 $\mathrm{m}$ from the ground-level) using Diameter Tape while their heights were measured with the help of Vertex IV and Transponder T3.

The Terai forests of Nepal host more than 100 tree species dominated by Sal (S. robusta), Teraimixed hardwood and Khair-Sissoo (A. catechu-D. sissoo) forests.

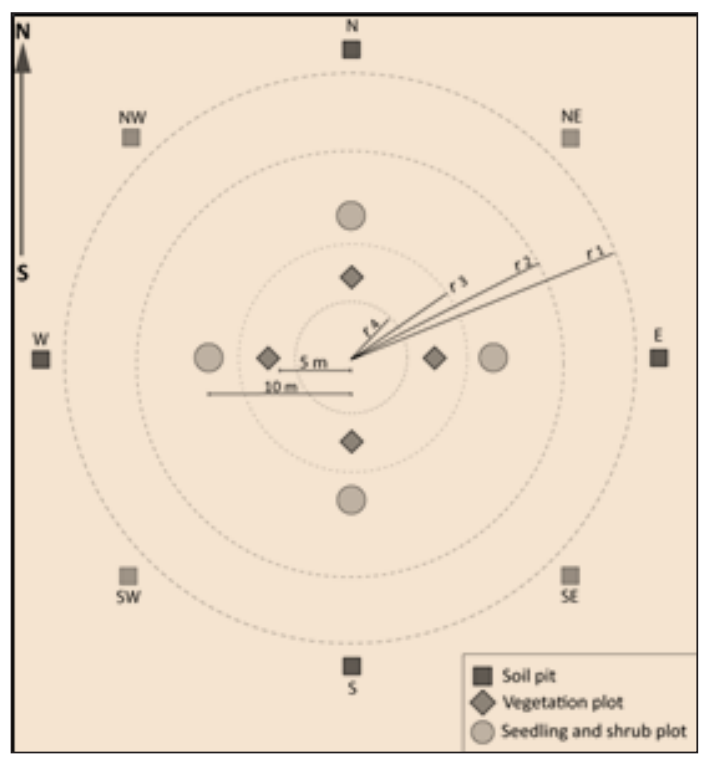

Fig. 1: Layout of a concentric circular sample plot

Note: symbols $r_{1}, r_{2}, r_{3}$ and $r_{4}$ are for radii $20 \mathrm{~m}$, $15 \mathrm{~m}, 8 \mathrm{~m}$ and $4 \mathrm{~m}$ respectively.

The selection of the species for the study was mainly based on the hierarchy in total count of the tallied trees in the sample plots (Table 1).

The data for the selected species consisted of

Table 1: Terai species taken for study purpose

\begin{tabular}{lllcc}
\hline S.N. & \multicolumn{1}{c}{ Species } & \multicolumn{1}{c}{ Local name } & $\begin{array}{c}\text { FRA database } \\
\text { code }\end{array}$ & $\begin{array}{c}\text { Number of } \\
\text { sampled trees }\end{array}$ \\
\hline 1. & Shorea robusta & Sal & 6615 & 1218 \\
2. & Terminalia alata & Asna/Saj & 6660 & 246 \\
3. & Mallotus philippensis & Sindhure & 6419 & 243 \\
4. & Lagerstroemia parviflora & Botdhangero & 6369 & 131 \\
5. & Anogeissus latifolia & Banjhi & 6113 & 112 \\
6. & Syzygium cumini & Jamun, Jamuno & 6651 & 110 \\
7. & Buchanania latifolia & Piyari & 6147 & 103 \\
8. & Dalbergia sissoo & Sissoo & 6239 & 67 \\
9. & Trewia nudiflora & Gutel/Velor & 6676 & 51 \\
\hline
\end{tabular}


the $\mathrm{dbh}>5 \mathrm{~cm}$ and the total tree heights of the sampled trees whose total heights were measured in the field inventory.

The data were handled with R-script in $\mathrm{R}$ Programme to generate non-linear mixed effects models in 'Imfor' package of Forest biometrics functions of Mehtatalo (2012). Different nonlinear models were used to fit the height-diameter relationship. All these models ensure that dbh is taken at $1.3 \mathrm{~m}$. Different non-linear models were used to fit the diameter-height relation, which performed well in describing the relationships between the diameters and the heights of the Terai tree species depending on the species and the sample sizes. The models were selected to be the "best fitted" based on the basis of the statistical results such as standard error, Adjusted $\mathrm{R}^{2}$, RMSE and residuals

\section{Results and discussion}

The best fitted models for estimating the volumes of the different Terai tree species are presented in Table 2, and are further represented in various graphs (Figures 1-10).

In Table 2, the best fitted model functions are presented for each species, where $\mathrm{a}, \mathrm{b}$ and $\mathrm{c}$ are values for coefficients in the equation. S.E. is standard error and RMSE is root mean squared error. Also $h(d)$, bh and d stand for predicted height for diameter (d), breast height and dbh respectively. The fitted model for $S$. robusta and T. alata were generated from Wykoff and Naslund functions with standard errors of 3.1 and 2.4, and adjusted $\mathrm{R}^{2}$ of 0.8 and 0.9 respectively. Besides, the minimum standard error of 1.8 was achieved in the Meyer model for A. latifolia whereas the maximum error of 3.1 was obtained in the Wykoff model for S. robusta. The graphs for standardized residuals vs. stand-wise standardized diameters and the graphs for the predicted vs. the measured heights are presented in Figures 2-10.

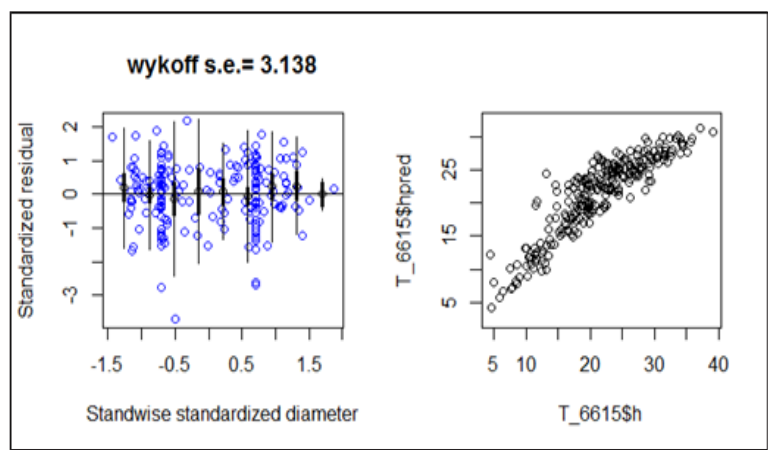

Fig. 2: Shorea robusta (6615)

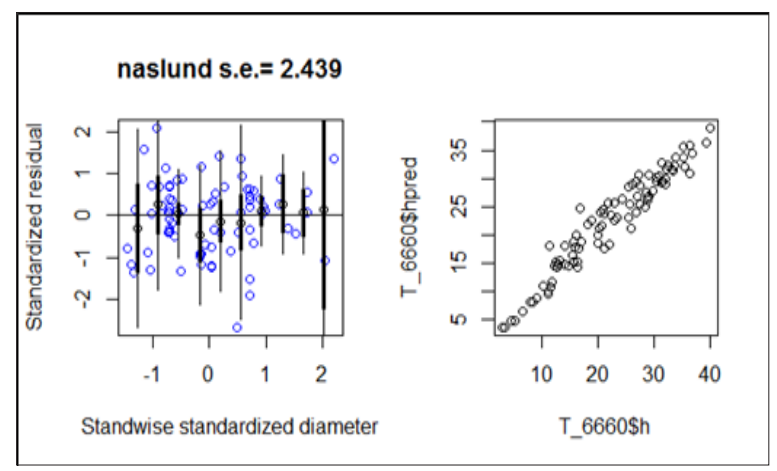

Fig. 3: Terminalia alata (6660)

Table 2: The best fitted models and their statistical validities

\begin{tabular}{|c|c|c|c|c|c|c|c|c|c|}
\hline S.N. & Species & $\begin{array}{l}\text { Model } \\
\text { function }\end{array}$ & Equation & $\mathbf{a}$ & b & c & S.E & Adj. $R^{2}$ & RMSE \\
\hline 1. & Shorea robusta & Wykoff & $\begin{array}{l}\mathrm{h}(\mathrm{d})=\mathrm{bh}+\exp (\mathrm{a}+\mathrm{b} / \\
(\mathrm{d}+1))\end{array}$ & 3.5034 & -13.7750 & - & 3.1 & 0.805 & 4.9720 \\
\hline 2. & $\begin{array}{l}\text { Terminalia } \\
\text { alata }\end{array}$ & Naslund & $\begin{array}{l}h(d)=b h+d^{\wedge} 2 /(a+b \\
d)^{\wedge} 2\end{array}$ & 2.2859 & 0.1529 & - & 2.4 & 0.931 & 4.6606 \\
\hline 3. & $\begin{array}{l}\text { Mallotus } \\
\text { philippensis }\end{array}$ & Michailoff & $h(d)=b h+a e^{\wedge}\left(-b d^{\wedge}(-1)\right)$ & 13.2790 & 6.1941 & - & 1.9 & 0.675 & 3.2543 \\
\hline 4. & $\begin{array}{l}\text { Lagerstroemia } \\
\text { parviflora }\end{array}$ & Meyer & $\begin{array}{l}h(d)=b h+a(1-\exp (-b \\
d))\end{array}$ & 17.3817 & 0.0719 & - & 2.0 & 0.933 & 4.6776 \\
\hline 5. & $\begin{array}{l}\text { Anogeissus } \\
\text { latifolius }\end{array}$ & Meyer & $\begin{array}{l}h(d)=b h+a(1-\exp (-b \\
\text { d) }\end{array}$ & 26.5472 & 0.0407 & - & 1.8 & 0.958 & 4.7934 \\
\hline 6. & $\begin{array}{l}\text { Syzygium } \\
\text { cumini }\end{array}$ & Naslund & $\begin{array}{l}h(d)=b h+d^{\wedge} 2 /(a+b \\
d)^{\wedge} 2\end{array}$ & 2.0245 & 0.2038 & - & 2.6 & 0.801 & 4.2454 \\
\hline 7. & $\begin{array}{l}\text { Buchanania } \\
\text { latifolia }\end{array}$ & Meyer & $\begin{array}{l}h(d)=b h+a(1-\exp (-b \\
d))\end{array}$ & 17.4584 & 0.0522 & - & 2.0 & 0.958 & 3.6739 \\
\hline 8. & $\begin{array}{l}\text { Dalbergia } \\
\text { sissoo }\end{array}$ & Ratkowsky & $\begin{array}{l}h(d)=b h+a \exp (-b /(d \\
+c))\end{array}$ & 22.4656 & 10.2333 & 3.699245 & 2.5 & 0.603 & 4.2237 \\
\hline 9. & $\begin{array}{l}\text { Trewia } \\
\text { nudiflora }\end{array}$ & Naslund & $\begin{array}{l}h(d)=b h+d^{\wedge} 2 /(a+b \\
d)^{\wedge} 2\end{array}$ & 1.0270 & 0.2388 & - & 2.5 & 0.507 & 3.9661 \\
\hline
\end{tabular}




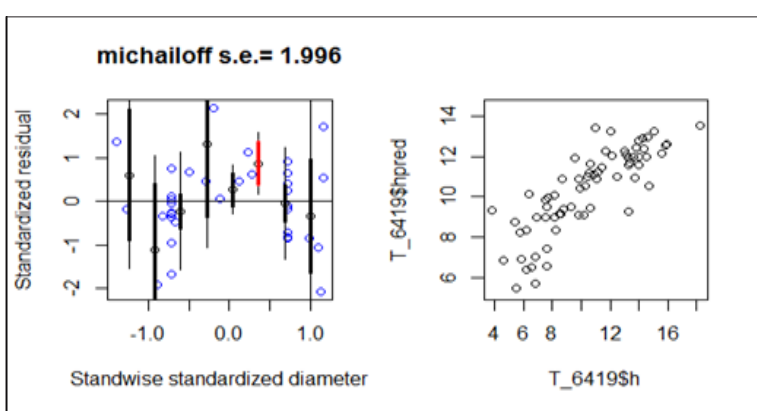

Fig. 4: Mallotus philippensis (6419)

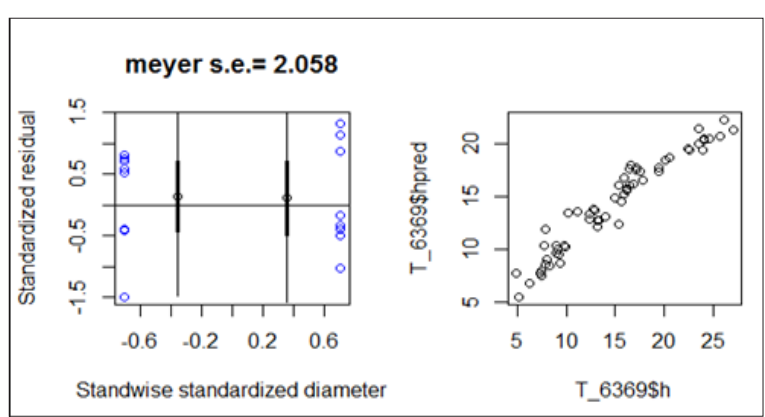

Fig. 5: Lagerstroemia parviflora (6369)

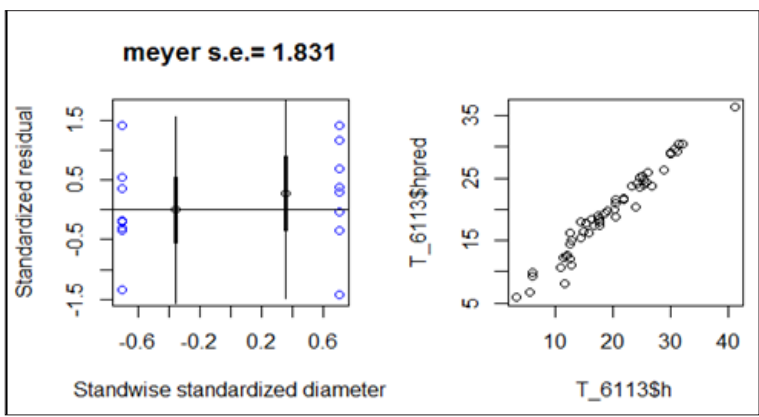

Fig. 6: Anogeissus latifolius (6113)

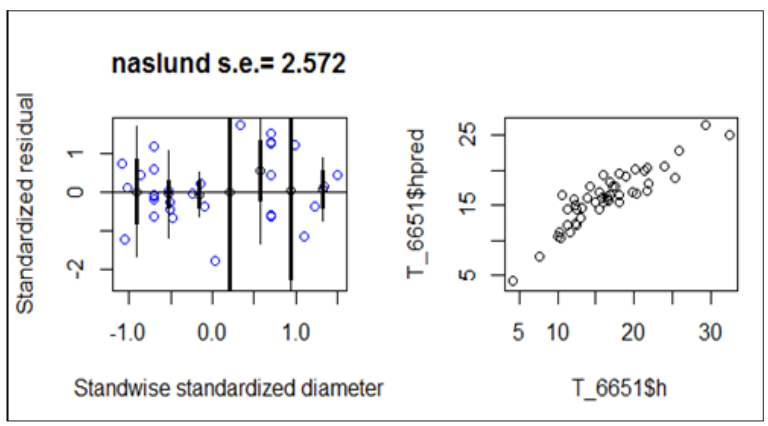

Fig. 7: Syzygium cumini (6651)

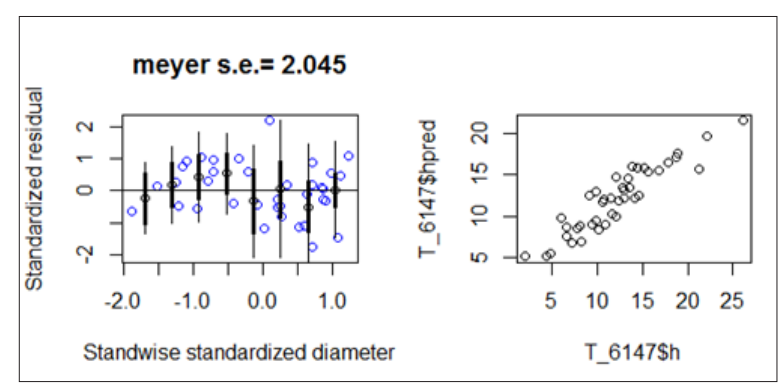

Fig. 8: Buchanania latifolia (6147) ratkowsky s.e. $=2.524$
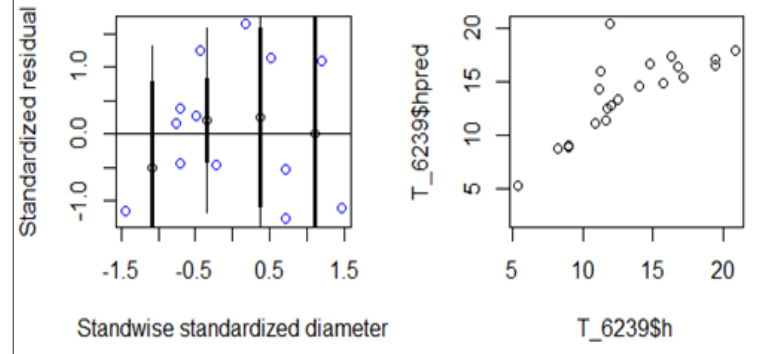

Fig. 9: Dalbergia sissoo (6239)

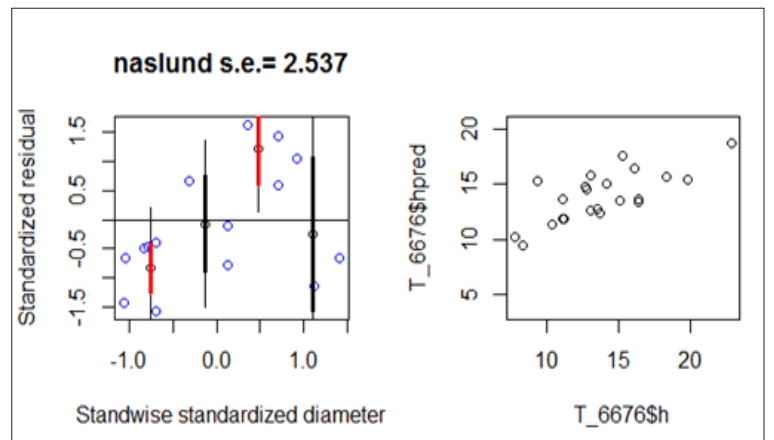

Fig. 10: Trewia nudiflora (6676)

Based on the results of this study, different nonlinear functions were found to have performed well in describing the relationships between the diameters and the heights of the Terai tree species depending on the sample size. Among the nine species, Meyer's function gave the best model for L. parviflora, A. latifolius and B. latifolia. Similarly, Naslund's function was found to be best suitable for T. alata, S. cumini and T. nudiflora. Likewise, the functions of Wykoff, Michailoff and Ratkowsky gave the best models for S. robusta, M. philippensis and D.sissoo respectively. Only Ratkowsky's function has three regression coefficients $(a, b, c)$, while the rest have only two ( $a$ and $b$ ). However, the FRA Nepal Project had used the mixed model, in which the plot location was also used as a random variable, for estimating the volume of the Terai tree species.

\section{Conclusion}

Although the above mentioned functions are generated for only one independent variable (diameter), they can be used for estimating the volume of the Terai tree species as per the findings of this study. 


\section{References}

Curtis, R. O. 1967. Height-diameter and heightdiameter-age equations for second-growth Douglas-fir. Forest Science 13: 365-375.

DFRS. 2014. Terai Forests of Nepal. Forest Resource Assessment Nepal Project/ Department of Forest Research and Survey, Kathmandu, Nepal.

Houghton, D. R. and Gregoire, T. G. 1993. Minimum subsamples of tree heights for accurate estimation of loblolly pine plot volume. Southern Journal of Applied Forestry 17: 124-129.

Lindstrom, M. J. and Bates, D. M. 1990. Nonlinear mixed effects for repeated measures data. Biometrics 46: 673-687.
Mamoun, E. I. and Osman, H. 2012. Modelling height-diameter relationships of selected economically important natural forests species. Journal of Forest products and industries 2 (1): 34-42.

Mehtatalo, L. 2012. Forest biometrics functions package 'Imfor'. Retrieved from: http://joyx. joensuu.fi/ lamehtat/documents/lmfor.pdf. Accessed on: 25th May 2012.

Meyer, H. A. 1940. A mathematical expression for height curves. Journal of Forestry 38: $415-420$. 